\title{
In situ CHARACTERISATION OF PALM OLEIN CRYSTALLISATION BEHAVIOUR BY FOCUSED BEAM REFLECTANCE MEASUREMENT (FBRM)
}

\author{
ELINA HISHAMUDDIN* and ZALIHA OMAR*
}

\begin{abstract}
This article examines the in situ characteristics and behaviour of particles during palm olein crystallisation using Focused Beam Reflectance Measurement (FBRM). Melted palm olein was isothermally crystallised at $9^{\circ} \mathrm{C}, 13^{\circ} \mathrm{C}$ and $15^{\circ} \mathrm{C}$ for $6 \mathrm{hr}$ in a stirred, jacketed vessel and changes in crystal size, population and behaviour were tracked using FBRM. Results indicate that the induction time for primary nucleation for palm olein increased while crystal population was significantly lower at higher temperatures, as expected. Crystallisation occurred in a two-step manner at $9^{\circ} \mathrm{C}$ and $13^{\circ} \mathrm{C}$ while a single step crystallisation was observed at $15^{\circ} \mathrm{C}$. These occurrences were plausibly due to the lower super cooling and fewer species of triacylglycerols capable of crystallising at higher temperatures. FBRM detected major agglomeration of crystals at $9^{\circ} \mathrm{C}$ due to increased crystal population and contact between crystals. Chord length distributions (CLD) showed that the final mode crystal size was $32 \mu \mathrm{m}$ at $9^{\circ} \mathrm{C}$ while significantly larger crystals of $108 \mu \mathrm{m}$ were observed at $15^{\circ} \mathrm{C}$. Microscopic observations revealed that crystals within the slurry appear gel-like below $13^{\circ} \mathrm{C}$. This study extends current knowledge on FBRM application for in situ particles characterisation in real time within a palm-based crystallisation system.
\end{abstract}

Keywords: palm olein; crystallisation; focused beam reflectance measurement (FBRM), crystal size distribution.

Date received: 29 May 2015; Sent for revision: 1 June 2015; Received in final form: 18 September 2015; Accepted: 20 November 2015.

\section{INTRODUCTION}

Palm olein is the liquid fraction produced from the fractionation process of palm oil. For the past several decades, palm olein has been industrially fractionated to produce sub-fractions with enhanced physical and chemical properties, termed as superolein and soft palm mid fraction. These sub-fractions find multiple usages for a variety of food products ranging from feedstock for the production of cooking and salad oils from the former to generating base stock

\footnotetext{
* Malaysian Palm Oil Board,

6 Persiaran Institusi, Bandar Baru Bangi,

43000 Kajang,Selangor, Malaysia.

E-mail: elina@mpob.gov.my
}

for margarines, shortenings and frying fats from the latter (Gibon and Tirtaux, 2002; Deffense, 2008). The first step in the fractionation process involves the crystallisation stage and the quality of the products obtained from fractionation in general strongly depends on the crystallisation operating conditions employed as well as the characteristics of crystals formed, which in turn affect the subsequent filtration stage (Deffense, 2009). It has been previously reported that the crystallisation of palm olein is often complicated by long crystallisation induction times, slow crystal growth rates and uneven crystal sizes (Siew and Ng, 1996; Deffense, 1998; Calliauw et al., 2007a). Previous studies have shown that optimal separation of crystals from the liquid fraction 
can be achieved when the crystals are uniform in shape, morphology and composition (Calliauw et al., 2007b). Therefore, an understanding of how operating conditions influence in-process changes in particle characteristics such as crystal size, population and behaviour is crucial to ensure proper control and optimisation is applied to the crystallisation operation, allowing better control of the finished product (Hartel, 2013).

In recent years, the availability of instruments which offer direct in situ measurement of particulate systems has made it possible to monitor real time changes in particle characteristics within different physical and chemical processes such as granulation, crystallisation, flocculation and dissolution (Fang et al., 2011). The Focused Beam Reflectance Measurement (FBRM) is a well-established method which has found extensive usage in online and in situ particle characterisation within the pharmaceutical and fine chemicals (Kougoulos et al., 2005; Nagy et al., 2008; Saleemi et al., 2012), food (Haddad Amamou et al., 2010; Arellano et al., 2012; Ndoye et al., 2013; Ndoye and Alvarez, 2015) and biotechnology industries (McDonald et al., 2001; Pearson et al., 2003; Jeffers et al., 2003; Whelan et al., 2012). This technique operates on the principle of laser backscattering wherein a laser beam scans in a circular path at a fixed speed through a probe immersed in the solution under study. As the laser beam intersects any two points on the edge of a particle within the solution, the beam is backscattered into the probe and returns a chord length, which is a function of the particle size and shape. The FBRM typically measures thousands of chord lengths per second within different size ranges and this translates to a chord length distribution (CLD) (Barrett and Glennon, 1999). Earlier studies have shown that the CLD data provided by FBRM gives an approximate correlation to the crystal size distribution (CSD), which makes it useful for following the evolution of crystal size within a slurry (Abu Bakar et al., 2010). The emergence of various crystallisation monitoring techniques such as the FBRM has enabled the acquisition of information not only limited to properties such as crystal size distribution, polymorphic forms and purity, which have a profound effect on the quality of final products and further downstream processes, but have also allowed one to follow the crystallisation mechanisms which continuously evolve throughout the entire process (Nagy et al., 2013).

Despite the wide-spread usage of FBRM within different crystallising mediums, its application within the edible oils and fats processing industry, however, still remains limited. Simon et al. (2009) reported one of the first studies on the use of FBRM for the detection of apparent nucleation of palm oil from the melt. Their study compared the bulk video monitoring (BVM) approach with FBRM and found that BVM was able to detect palm oil nucleation earlier compared to FBRM. The BVM detected a cloud formation in the bulk which was attributed to a large number of small crystals having sizes below the FBRM detection limit. Hishamuddin et al. (2011) subsequently demonstrated that the FBRM technique was capable of providing valuable information on the dynamic evolution of particle characteristics and detection of multiple events related to the crystallisation and melting of palm oil. They successfully characterised multiple crystallisation events such as primary and secondary nucleation, crystal growth, agglomeration and deagglomeration of solid crystals within the palm oil system based on the total particle counts, mean chord length and CLD data obtained from FBRM.

This article reports an investigation on the particle characteristics and evolution of palm olein crystallisation at different isothermal temperatures in situ and in real time using the FBRM probe. The FBRM response is further corroborated with optical microscopy for the characterisation of the behaviour, size and morphology of crystals within a palm olein crystallisation system.

\section{MATERIALS AND METHODS}

\section{Materials}

Refined, bleached and deodorised (RBD) palm olein with an iodine value of 56.5 was purchased from MOI Foods Malaysia Sdn Bhd (Pulau Indah, Selangor, Malaysia). The oil was heated and homogenised at $60^{\circ} \mathrm{C}$ for $30 \mathrm{~min}$ to ensure complete melting of any crystals that may be present within the oil prior to performing the crystallisation experiments.

\section{Crystallisation Process}

Crystallisation of palm olein was performed in a LabMax Automatic Lab Reactor (Mettler Toledo, Redmond, WA, USA). Approximately $700 \mathrm{ml}$ of the melted palm olein was crystallised in a 1 litre glass jacketed vessel and continuous monitoring of the crystals behaviour within the slurry was achieved using a Lasentec FBRM probe Model D600L (Mettler Toledo, Redmond, WA, USA) which was installed through the top of the vessel (Figure 1). The oil was crystallised isothermally at $9^{\circ} \mathrm{C}, 13^{\circ} \mathrm{C}$ and $15^{\circ} \mathrm{C}$. The crystallisation programme applied to the melted palm olein at each temperature was as follows: heat at $65^{\circ} \mathrm{C}$ for $15 \mathrm{~min}$, cool down to $30^{\circ} \mathrm{C}$ in $20 \mathrm{~min}$, cool down further to the desired isothermal temperature at a cooling rate of $0.5^{\circ} \mathrm{C} \mathrm{min}{ }^{-1}$ and finally hold at isothermal temperature for $6 \mathrm{hr}$. The agitation speed was maintained at $50 \mathrm{rpm}$. FBRM recorded real time data on crystal characteristics such as crystals population, evolution of mean crystal size as well as 


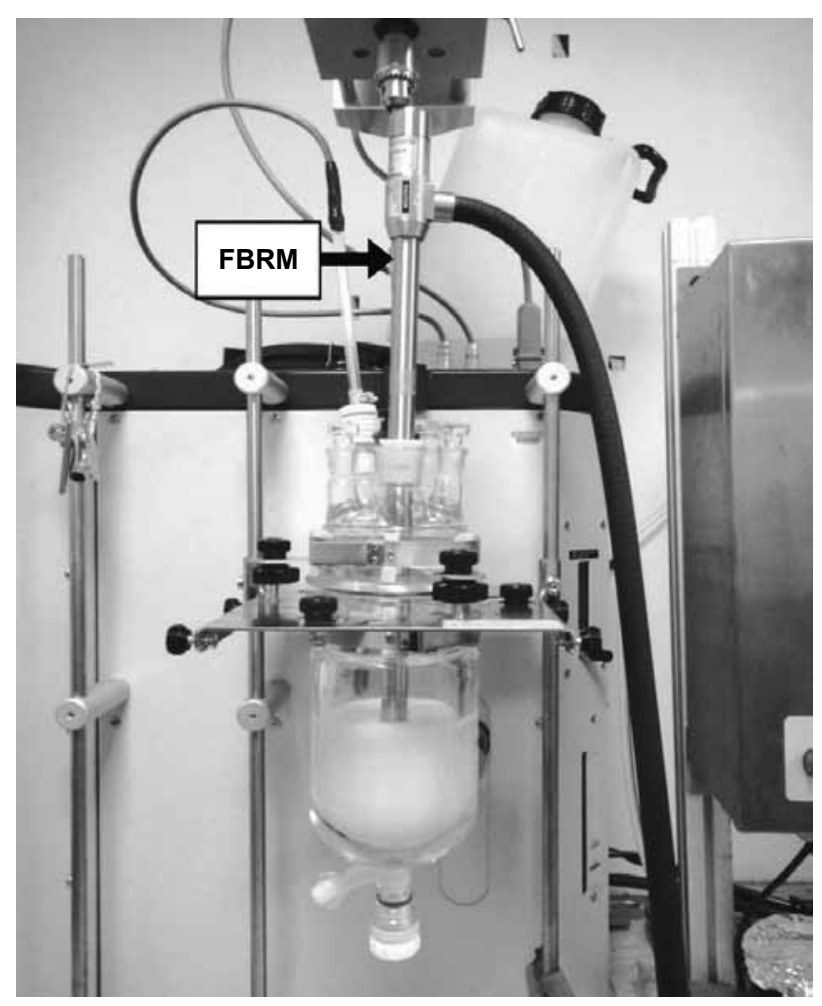

Figure 1. The experimental crystallisation rig used in this study showing the Focused Beam Reflectance Measurement (FBRM).

crystal size distribution of particles within the slurry every $30 \mathrm{~s}$. The FBRM data was further analysed using the Lasentec FBRM Data Review software (Mettler Toledo, Redmond, WA, USA). Heath et al. (2002) reported that the square-weighted chord length measurements from the FBRM were found to be comparable to conventional particle sizing techniques. Hence, the square-weighted chord length measurements were used to describe the experimental results obtained from FBRM.

\section{Morphological Analysis}

The crystallising slurry was sampled and the morphology of crystals was observed using optical microscopy. Crystals were visually examined using a Leica DMLP polarised light microscope equipped with a temperature-controlled stage (Linkam TP94 and LNP). Images were captured and processed using Leica Qwin software (version 3.0, Leica Microsystems Digital Imaging, Cambridge) at 20X magnification.

\section{RESULTS AND DISCUSSION}

\section{In situ Monitoring of Palm Olein Crystallisation by FBRM}

The evolution of the crystal populations, expressed as the total counts of particles detected per second, as a function of the isothermal holding time at $9^{\circ} \mathrm{C}, 13^{\circ} \mathrm{C}$ and $15^{\circ} \mathrm{C}$ are illustrated in Figure 2. As expected, the induction time for primary nucleation increases at higher isothermal temperatures due to the lower supercooling applied. At lower temperatures, a considerably higher nucleation rate and a higher population of crystals was observed. A maximum of 6500 counts/s of crystals were present at $9^{\circ} \mathrm{C}$ while a significantly lower crystal population of 300 counts $/ \mathrm{s}$ was observed at $15^{\circ} \mathrm{C}$. Subjecting a low supercooling to palm olein would result in a longer induction time as the system relies on spontaneous heterogeneous nucleation to occur on impurities or on the wall of the crystalliser (Deffense, 1998; Deffense, 2009). Also, the near absence of trisaturated triacylglycerol (TAG) such as tripalmitin (PPP) in palm olein which act as the first nuclei as in the case of palm oil, makes it more difficult for palm olein to crystallise and thus, it is the diacylglycerols then that are responsible in assisting in the formation of the first nuclei (Calliauw et al., 2007a).

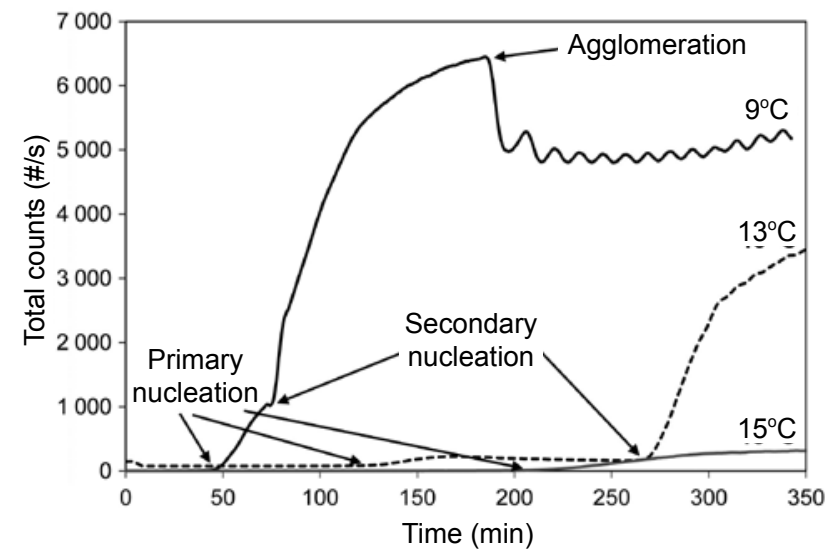

Figure 2. Total particle counts as a function of time at $9^{\circ} \mathrm{C}$, $13^{\circ} \mathrm{C}$ and $15^{\circ} \mathrm{C}$

It can also be seen that crystallisation of palm olein occurred in a two-step manner involving primary and secondary nucleation events at isothermal temperatures of $13^{\circ} \mathrm{C}$ and below. This can be deduced from the two successive increases in the total counts which indicate two nucleation events occurring in sequence. The single-step crystallisation observed at $15^{\circ} \mathrm{C}$ is largely attributed to the lower supercooling involved at this temperature which entails less crystallisation driving force, causing plausibly the major monounsaturated triacylglycerol component within the palm olein, i.e. dipalmitoyl-oleoyl-glycerol (POP) to crystallise and remain in the crystal form. The two-step crystallisation observed below $13^{\circ} \mathrm{C}$ could be a result of the secondary crystallisation of a mixture of crystals containing POP together with palmitoyl-stearoyl-oleoyl-glycerol (POS) and palmitoyl-linoleoyl-glycerol (PLP) as previously reported by Calliauw et al. (2007b).

At $9^{\circ} \mathrm{C}$, a sudden drop in the total particle counts towards the middle of the experiment (around 185 
min) could be observed, signifying the occurrence of an apparent agglomeration event. This phenomenon, however, did not occur at $13^{\circ} \mathrm{C}$ and $15^{\circ} \mathrm{C}$. A further comparison between the mean chord length and total particle counts when the palm olein was subjected to isothermal crystallisation at $9^{\circ} \mathrm{C}$ is shown in Figure $3 a$. The sudden drop in the total counts correspond to a sudden increase in the mean chord length from $47 \mu \mathrm{m}$ to $51 \mu \mathrm{m}$, confirming the rapid agglomeration of crystals taking place at this temperature. This can be explained by the fact that the larger supercooling applied at $9^{\circ} \mathrm{C}$ would result in a higher crystal population due to the larger number of nuclei formed, thereby allowing increased contact between crystals. This would subsequently promote the agglomeration process through crystals attachment and contribute to the increase in mean crystal sizes. According to Deffense (2009), excessive nucleation takes place during the crystallisation supercooling of palm olein in the absence of seeding and thus results in a large number of particles, as observed in this case at $9^{\circ} \mathrm{C}$. The larger number of crystals present at these lower temperatures consequently causes small crystals to group together in soft crystal clumps (Deffense, 1998). This explains why agglomeration was more significant at $9^{\circ} \mathrm{C}$ compared to that at higher temperatures.

Following the sudden agglomeration event, both the mean chord length and total counts responses subsequently show oscillating behaviour until

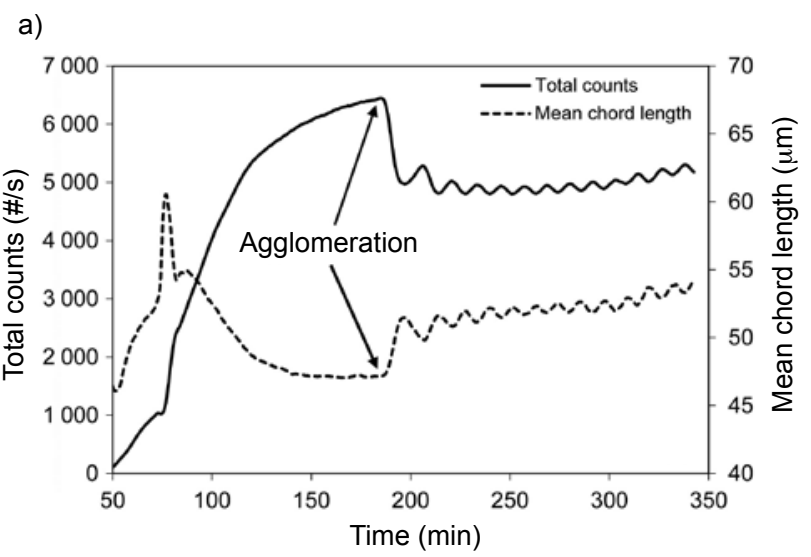

b)

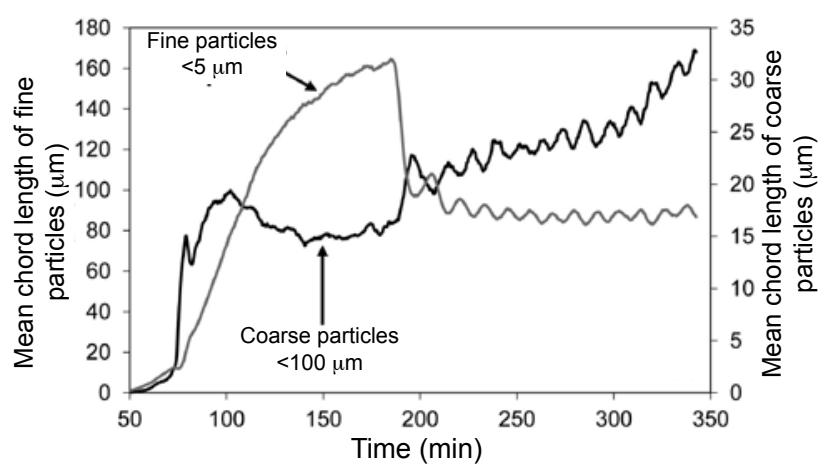

Figure 3. (a) Mean chord length and total particle counts as a function of time at $9^{\circ} \mathrm{C}$. (b) Fine and coarse particle counts as a function of time at $9^{\circ} \mathrm{C}$. the end of the experiment (Figure 3a). Upon closer examination of the fine $(<5 \mu \mathrm{m})$ and coarse $(>100$ $\mu \mathrm{m})$ particle counts profiles as presented in Figure $3 b$, it was observed that the characteristic rises and dips between the two are out-of-phase with one another, indicating the possibility of an agglomerationdeagglomeration of the particles which occur in a cyclic manner within the palm olein slurry. It cannot be ruled out that dissolution-recrystallisation of the fine crystals could have also taken place within the slurry as the oscillation behaviour observed in the total and fine particle counts responses are in well agreement with each other. The postulated mechanism of a cyclic agglomerationdeagglomeration appears to also happen at a greater rate compared to the dissolution-crystallisation of fines, as evident from the increasing trend in the coarse particle counts. This specific evolution of particles behaviour was similarly observed in repeat experiments at the same temperature, confirming this as a genuine phenomenon which takes place during palm olein crystallisation at $9^{\circ} \mathrm{C}$.

An explanation for this behaviour could be due to the significantly higher viscosity within the slurry which increases rapidly at lower temperatures, possibly causing poor heat transfer from the crystalliser wall to the slurry within the immediate surroundings of the probe tip. Variations in the mixing conditions and the probability of a localised measurement of the crystals in the immediate vicinity of the probe as a result of the type of agitator used in this study may also have affected the measurements with increasing slurry viscosity. The FBRM measurements have previously been shown to be dependent on crystals density and stirring conditions near the probe (Heath et al., 2002). In an oil or fat crystallising system, high viscosity conditions limit diffusivity and the overall growth rate consequently decreases due to mass transport limitations (Himawan et al., 2006).

To explore further the secondary nucleation event which took place at $13^{\circ} \mathrm{C}$, the evolution of the mean particle size expressed as mean chord length and total counts of palm olein crystallised at $13^{\circ} \mathrm{C}$ as a function of time are shown in Figure $4 a$. It can be seen that the induction time for primary nucleation was approximately $125 \mathrm{~min}$ into the isothermal holding time, signified by the first surge in total counts. The total counts then stabilised until 270 min while the mean chord length of crystals simultaneously increased at a larger rate, indicative of rapid crystal growth which occurs in parallel with the primary nucleation process. A sharp, second increase in total counts subsequently occurred at $270 \mathrm{~min}$, which coincided with a sudden drop in the mean chord length from $80 \mu \mathrm{m}$ to $67 \mu \mathrm{m}$ between $250 \mathrm{~min}$ to $270 \mathrm{~min}$, indicating the rise in the number of slightly smaller particles within the crystalliser through secondary nucleation. The mean chord 
length eventually stabilised at approximately 70 $\mu \mathrm{m}$ although the total particle counts continued to increase until the end of the experiment. It is worth to note that simultaneous to the second surge in total counts from 250 min onwards in Figure $4 a$, a slight increase in the temperature of the slurry was observed from $13^{\circ} \mathrm{C}$ to $13.85^{\circ} \mathrm{C}$ despite the isothermal set point temperature being maintained at $13^{\circ} \mathrm{C}$. A rise in the slurry temperature strongly suggests the release of the latent heat of crystallisation into the process as a direct consequence of new crystals forming either directly from the melt or from crystal breakage, in combination with the aggregation of existing crystals. Removal of the heat generated by these events from the crystal surface is necessary in order to maintain the desired isothermal temperature within the slurry. It has been previously reported that the viscosity of an oil melt significantly affects crystal growth rate at higher degrees of supercooling, as higher viscosities tend to limit the diffusion of molecules and the transfer of the latent heat of crystallisation away from the crystal surface (Marangoni, 2005). Therefore, this explains how the occurrence of the multiple crystallisationdissolution events as previously described caused the subsequent minor increase in slurry temperature within the palm olein system.

a)

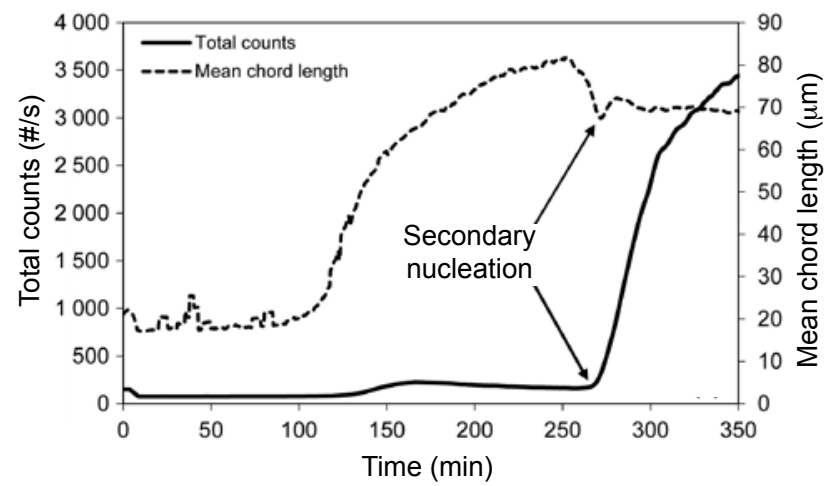

b)

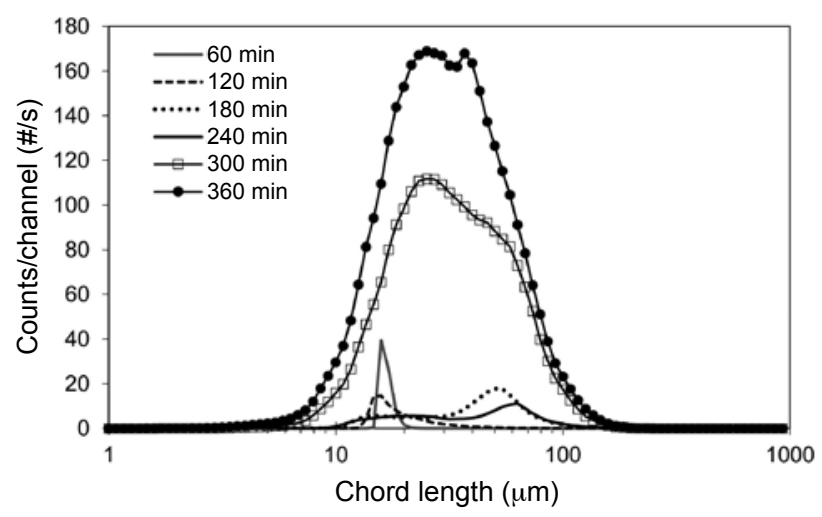

Figure 4. (a) Mean chord length and total counts as a function of time at $13^{\circ} \mathrm{C}$. (b) Effect of isothermal time on the evolution of chord length distribution of particles at $13^{\circ} \mathrm{C}$.
If we examine the evolution of the CLD of the crystals as illustrated in Figure $4 b$, the CLD is seen to shift from $15 \mu \mathrm{m}$ to $68 \mu \mathrm{m}$ between 60 to $240 \mathrm{~min}$, confirming the occurrence of crystal growth while crystal numbers remain relatively low. Between 240 and $300 \mathrm{~min}$, there is a substantial growth in the population of crystals as depicted by the large increase in the area under the distribution in combination with a shift in the CLD towards smaller sizes with increasing isothermal time. This suggests the generation of new crystals either directly from the melt or as a direct consequence of attrition through crystal contact which occurs concurrently with the growth of existing crystals through aggregation. Nucleation and crystal growth form the main crystallisation events in oils and fats systems; however these two phenomena are not mutually exclusive and may take place simultaneously as they are difficult to distinguish (Marangoni, 2005). Hence, the contributing effects of these two phenomena are mainly responsible for the large growth in crystal population and size between 240 to $360 \mathrm{~min}$ as depicted in Figure $4 b$.

\section{Palm Olein CLD Measurements by FBRM}

A comparison between the final size distributions of crystals obtained at all isothermal temperatures in study can be made by observing the CLD at the end of the experiments. Figure 5 illustrates the final CLD of palm olein crystals at the end of the experiments at $9^{\circ} \mathrm{C}, 13^{\circ} \mathrm{C}$ and $15^{\circ} \mathrm{C}$. Crystal sizes were larger and the population of crystals was significantly lower when a higher isothermal temperature was employed. This is depicted by the considerably smaller area under the distribution at $15^{\circ} \mathrm{C}$ which is located within the greater size region compared to that observed at $9^{\circ} \mathrm{C}$ and $13^{\circ} \mathrm{C}$, further corroborating the earlier results from the total counts profiles in Figure 2. The mode crystal size more than trebled from approximately $32 \mu \mathrm{m}$ obtained at the lower temperature of $9^{\circ} \mathrm{C}$ compared to $108 \mu \mathrm{m}$ at $15^{\circ} \mathrm{C}$. This is plausibly due to the insufficient supercooling at $15^{\circ} \mathrm{C}$ which only permits higher melting TAG within palm olein such as POP, to crystallise in limited amounts and any further crystallisation then proceeds on these initial crystals, allowing them to grow into larger crystal entities. The same observation was reported by Hishamuddin et al. (2011) in their study on palm oil.

\section{Morphology of Palm Olein Crystals}

Microscopic images of palm olein crystals further supported the CLD data from the FBRM, as shown in Figures $6 a, 6 b$ and $6 c$. A higher quantity of small, closely packed, gel-like crystals was observed at $9^{\circ} \mathrm{C}$ (Figure $6 a$ ) while at $15^{\circ} \mathrm{C}$, larger crystals in the 


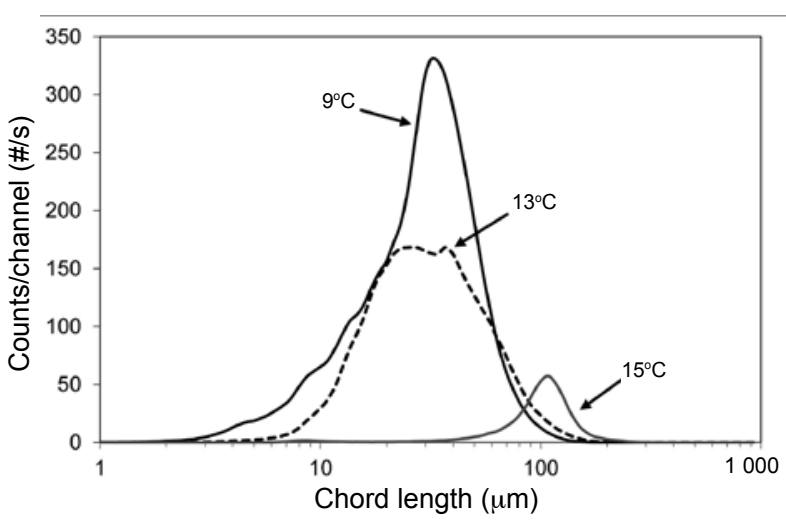

Figure 5. Effect of isothermal temperatures on the final chord length distribution of palm olein crystals.

form of big and dense agglomerates were present in fewer numbers surrounded by uncrystallised liquid (Figure 6c). A mixture of spherulites and agglomerates of varying sizes were formed at $13^{\circ} \mathrm{C}$ as shown in Figure $6 b$. The microscopic images of samples presented here appear to be consistent with the FBRM data, reflecting the population and size distribution of crystals within the crystallising slurry.

At $9^{\circ} \mathrm{C}$, the appearance of a near transparent, gel-like structure appears to be similar to an earlier study by Calliauw et al. (2007a) which reported changes in crystal surface appearances possibly due to POS crystals being increasingly incorporated into the existing POP crystal. Deffense (2009) suggested this material as a vitreous phase known as olein crystallising in amorphous form. The gellike layer surrounding crystals at $9^{\circ} \mathrm{C}$ in Figure $6 a$ is thought to be a mixture of not only different species of monounsaturated TAG but also includes diunsaturated mainly [dioleoyl-palmitoyl-glycerol (POO)] and triunsaturated TAG within the gel structure. This observation was also reported by Calliauw et al. (2010) when they observed a 'sticky' and viscous secondary layer forming around the initial crystals due to the increase in slurry viscosity and our observation appears to mimic the gel-like material comprising of irregular lumps of spherulites, as described by Shi et al. (2005) in their model lipid system comprising of a mixture of disaturated and triunsaturated long-chain TAG.

\section{CONCLUSION}

This study demonstrates how the FBRM can be a useful tool to investigate in situ particle characteristics within a dynamic palm olein crystallisation system in real time. Real time changes in crystal size distribution, crystal population

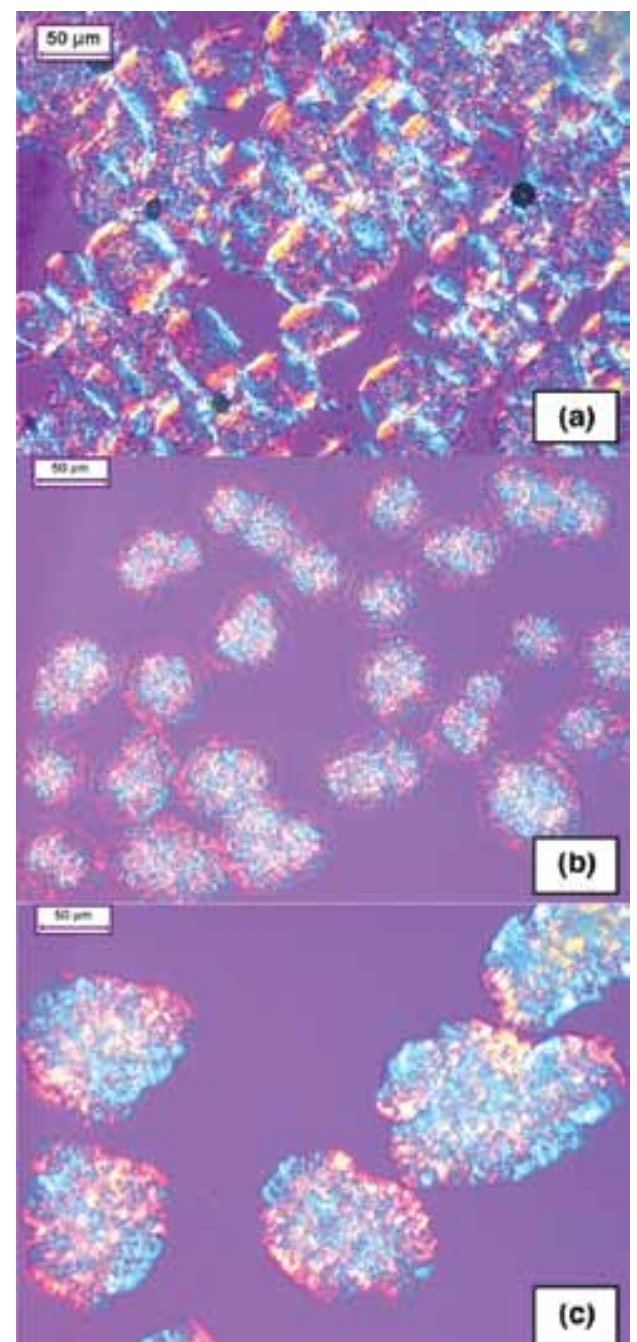

Figure 6. Microscopic images of palm olein crystals at: (a) $9^{\circ} \mathrm{C}$, (b) $13^{\circ} \mathrm{C}$ and (c) $15^{\circ} \mathrm{C}$ at the end of each experiment (magnification 20X).

and crystallisation behaviour of palm olein were characterised throughout the entire crystallisation process at different isothermal conditions using the FBRM. At crystallisation temperatures below $15^{\circ} \mathrm{C}$, a two-step crystallisation mechanism was detected coupled with a reduction in crystal sizes and increasing crystal population. Agglomeration was more pronounced at lower temperatures due to the larger number of crystals resulting from increased supercooling levels. Microscopic imaging observations further corroborated FBRM responses on the crystallisation behaviour of palm olein. The application of FBRM in palm-based crystallisation processes has been shown to provide valuable inprocess information, enabling proper control of crystallisation conditions to produce the preferred crystals characteristics. This will greatly enhance the separation efficiency during the filtration stage and ultimately the desired end product quality can be achieved. 


\section{REFERENCES}

ABU BAKAR, M R; NAGY, Z K and RIELLY, C D (2010). Investigation of the effect of temperature cycling on surface features of sulfathiazole crystals during seeded batch cooling crystallization. Cryst. Growth Des., 10(9): 3892-3900. DOI: 10.1021/ cg1002379.

ARELLANO, M; BENKHELIFA, H; FLICH, D and ALVAREZ, G (2012). Online ice crystal size measurements during sorbet freezing by means of the focused beam reflectance measurement (FBRM) technology. Influence of operating conditions. J. Food Eng., 113(2): 351-359. DOI: 10.1016/j.jfoodeng.2012.05.016.

BARRET, T P and GLENNON, B (1999). In-line FBRM monitoring of particle size in dilute agitated suspensions. Part. Part. Syst. Charact., 16(5): 207-211. DOI: 10.1002 / (SICI)1521-4117(199910)16:5<207:AIDPPSC207>3.0.CO;2-U.

CALLIAUW, G H; GIBON, V and DE GREYT, W F J (2007a). Principles of palm olein fractionation: a bit of science behind the technology. Lipid Technol., 19(7): 152-155. DOI: 10.1002/lite.200700050.

CALLIAUW, G; GIBON, V; DE GREYT, W; PLEES, L; FOUBERT, I and DEWETTINCK, K (2007b). Phase composition during palm olein fractionation and its effect on soft PMF and superolein quality. J. Amer. Oil Chem. Soc., 84(9): 885-891. DOI: 10.1007/s11746-007-1118-5.

CALLIAUW, G; FREDRICK, E; GIBON, V; DE GREYT, W; WOUTERS, J; FOUBERT, I and DEWETTINCK, K (2010). On the fractional crystallization of palm olein: solid solutions and eutectic solidification. Food Res. Int., 43(4): 972-981. DOI:10.1016/j.foodres.2010.01.002.

DEFFENSE, E (1998). Dry fractionation and selectivity: innovations technologies. OCL, 5(5): 391-395. http: / / cat.inist.fr $/$ ?aModele $=$ afficheN\&cpsid $t=1639208$

DEFFENSE, E (2008). Fractionation to produce novel oleins and stearins for the food and shortening market. AgroFOOD Industry Hi-Tech, 19(3): 67-68.

DEFFENSE, E (2009). From organic chemistry to fat and oil chemistry. OCL, 16(1): 14-24. DOI:http:/ / dx.doi.org/10.1051/ ocl.2009.0238

FANG, Y; SELOMULYA, C; AINSWORTH, S; PALMER, M and CHEN, X D (2011). On quantifying the dissolution behaviour of milk protein concentrate. Food Hydrocolloids, 25(3): 503-510. DOI:10.1016/j. foodhyd.2010.07.030.
GIBON, V and TIRTAUX, A (2002). Latest trends in dry fractionation. Lipid Technol., 23(3): 33-36.

HADDAD AMAMOU, A; BENKHELIFA, H; ALVAREZ, G and FLICK, D (2010). Study of crystal size evolution by focused-beam reflectance measurement during the freezing of sucrose/water solutions in a scraped-surface heat exchanger. Process Biochem., 45(11): 1821-1825. DOI:10.1016/j. procbio.2010.04.001.

HARTEL, R W (2013). Advances in food crystallization. Annu. Rev. Food Sci. Technol., 4: 277292. DOI: 10.1146/ annurev-food-030212-182530.

HEATH, A R; FAWELL, P D; BAHRI, P A and SWIFT, J D (2002). Estimating average particle size by focused beam reflectance measurement (FBRM). Part. Part. Syst. Charact., 19(2): 84-95. DOI: 10.1002 /1521-4117(200205)19:2<84::AIDPPSC84>3.0.CO;2-1.

HIMAWAN, C; STAROV, V M and STAPLEY, A G F (2006). Thermodynamic and kinetic aspects of fat crystallization. Adv. Colloid Interface Sci., 122: 3-33.

DOI:10.1016/j.cis.2006.06.016.

HISHAMUDDIN, E; STAPLEY, A G F and NAGY, Z K (2011). Application of laser backscattering for monitoring of palm oil crystallisation from melt. J. Cryst. Growth, 335(1): 172-180. DOI:10.1016/j. jcrysgro.2011.09.033.

JEFFERS, P; RAPOSO, S; LIMA-COSTA, M E I; CONNOLLY, P; GLENNON, B and KIERAN, P M (2003). Focussed beam reflectance measurement (FBRM) monitoring of particle size and morphology in suspension cultures of Morinda citrifolia and Centaurea calcitrapa. Biotechnol. Lett., 25(23): 20232028. DOI:10.1023/B:BILE.0000004396.97796.0c.

KOUGOULOS, E; JONES, A G; JENNINGS, K $\mathrm{H}$ and WOOD-KACZMAR, M W (2005). Use of focused beam reflectance measurement (FBRM) and process video imaging (PVI) in a modified mixed suspension mixed product removal (MSMPR) cooling crystallizer. J. Cryst. Growth, 273(3): 529-534. DOI:10.1016/j.jcrysgro.2004.09.032.

MARANGONI, A G (2005). Crystallization kinetics. Fat Crystal Networks (Marangoni, A G ed.). Marcel Dekker, Inc., p. 21-82. https://books.google.com. my / books?isbn $=142003054$ X.

MCDONALD, K A; JACKMAN, A P and HURST, $S$ (2001). Characterization of plant suspension cultures using the focused beam reflectance technique. Biotechnol. Lett., 23(4): 317-324. DOI: 10.1023 / A:1005646826204. 
NAGY, Z K; CHEW, J W; FUJIWARA, $M$ and BRAATZ, R D (2008). Comparative performance of concentration and temperature controlled batch crystallizations. J. Proc. Contr., 18(3): 399-407. DOI:10.1016/j.jprocont.2007.10.006.

NAGY, Z K; FEVOTTE, G; KRAMER, $\mathrm{H}$ and SIMON, L L (2013). Recent advances in the monitoring, modelling and control of crystallization systems. Chem. Eng. Res. Des., 91(10): 1903-1922. DOI:10.1016/j.cherd.2013.07.018.

NDOYE, F T; ERABIT, N; FLICK, D and ALVAREZ, G (2013). In-line characterization of a whey protein aggregation process: aggregates size and rheological measurements. J. Food Eng., 115(1): 73-82. DOI:10.1016/j.jfoodeng.2012.09.021.

NDOYE, $\mathrm{F}$ T and ALVAREZ, G (2015). Characterization of ice recrystallization in ice cream during storage using the focused beam reflectance measurement. J. Food Eng., 148: 24-34. DOI:10.1016/j. jfoodeng.2014.09.014.

PEARSON, A P; GLENNON, B and KIERAN, P M (2003). Comparison of morphological characteristics of Streptomyces natalensis by image analysis and focused beam reflectance measurement. Biotechnol. Progr., 19(4): 1342-1347. DOI: 10.1021/bp025734p.

SALEEMI, A $\mathrm{N}$; STEELE, G; PEDGE, $\mathrm{N}$ I; FREEMAN, A and NAGY, Z K (2012). Enhancing crystalline properties of a cardiovascular active pharmaceutical ingredient using a process analytical technology based crystallization feedback control strategy. Int. J. Pharm., 430: 56-64. DOI:10.1016/j. ijpharm.2012.03.029.
SHI, Y; LIANG, B and HARTEL, R W (2005). Crystal morphology, microstructure, and textural properties of model lipid systems. J. Amer. Oil Chem. Soc., 82(6): 399-408. DOI: 10.1007/ s11746-005-1084-3.

SIEW, W L and NG, W L (1996). Effect of diglycerides on the crystallisation of palm oleins. J. Sci. Food Agric., 71(4): 496-500. DOI: 10.1002/(SICI)10970010(199608)71:4<496::AID-JSFA616>3.0.CO;2-W.

SIMON, L L; NAGY, Z K and HUNGERBUHLER, K (2009). Comparison of external bulk video imaging with focused beam reflectance measurement and ultra-violet visible spectroscopy for metastable zone identification in food and pharmaceutical crystallization processes. Chem. Eng. Sci., 64(14): 3344-3351. DOI:10.1016/j.ces.2009.04.016.

WHELAN, J; MURPHY, E; PEARSON, A; JEFFERS, P; KIERAN, P; MCDONNELL, $S$ and GLENNON, $B$ (2012). Use of focussed beam reflectance measurement (FBRM) for monitoring changes in biomass concentration. Bioprocess Biosyst. Eng., 35(6): 963-975. DOI:10.1007 / s00449-012-0681-9. 